\title{
Astronomers and squirrels in new clash over telescope
}

Washington. A long-running feud between US astronomers and conservationists has erupted once more in the mountains of Arizona, delaying the construction of what will eventually be one of the world's most powerful ground-based telescopes.

The Tucson district court ruled at the end of last month that site preparation for the Large Binocular Telescope (LBT) on Mount Graham should be halted pending new environmental impact studies, following a decision to shift its site by 400 yards from that originally planned.

The University of Arizona - which is building the $\$ 60$-million telescope together with the Research Corporation of Tucson and an Italian consortium led by the Arcetri Astrophysical Observatory in Florence plans to appeal against the ruling.

But this latest twist in a tortuous 14-year saga has increased concern among astronomers that environmental pressure to protect the wilderness may eventually make it impossible to build new telescopes on any desirable site in the United States.

Mount Graham was originally chosen as the site of an international observatory because, unusually for a suitably remote mountain in the dry American southwest, it already had some tourist development and good road access.

But, in the latest of ten court battles, Alfredo C. Marquez, a district court judge, ruled on 28 July that, by allowing the university to shift the site of the new telescope, the US Forest Service and Fish and Wildlife Service had breached a 1988 agreement allowing the observatory to be built.

A coalition of local and national environmental groups brought the case to court when the university cleared 250 trees from the new site last December. They argue that the observatory already damages a small and retreating ecosystem at the top of Mount Graham, threatens the future of a nowfamous subspecies, the Mount Graham Red Squirrel, and offends San Carlos Apaches, who consider the mountain to be sacred.

The LBT would be the third and largest telescope at the site. Sitting on top of a 100foot tower on one acre of land in the middle of nowhere, this pristine machine does not appear to be the gravest threat facing the environment of the continental United States. But try explaining that to the red squirrel, says Roger Featherstone, a long-standing opponent of the project, who now works with the Endangered Species Coalition in Washington, DC.

Featherstone says that the top of Mount Graham consists of 600 unique acres of mixed spruce and fir, and describes it as "a little piece of the north Canadian ecosys- tem" in Arizona. "We're talking about a very tiny ecosystem," he says. "The third telescope would be the largest and most destructive."

The squirrel is one of 25 red subspecies found in North America. When it was listed under the Endangered Species Act in 1987, it was thought to survive only in the spruce and fir environment at the mountain top, and

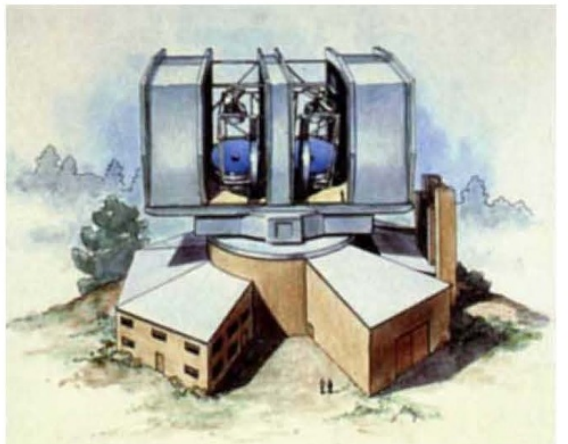

The Large Binocular Telescope being planned by the University of Arizona.

the observatory had to obtain an exemption from Congress to build on the land.

But the University of Arizona, which employs five full-time biologists to watch the squirrels and pays $\$ 50,000$ a year to the Forest Service towards research on their habitat, now thinks they are also thriving further down the mountain.

Peter Strittmatter, director of the Steward Observatory, says he has been told that the new site for the LBT contains even fewer squirrels than the original one. But opponents say that the main point is that the university broke the law by shifting the site.

"At 4.30 in the morning, in the middle of the winter, they clear-cut those trees," says Bob Witzeman, a retired Phoenix physician and long-standing opponent of the project, who claims that the act was illegal. "We started at the crack of dawn as we always do," retorts Strittmatter. "The Forest Service gave us the authority to do it."

The argument will continue in court. The university last week filed an emergency motion asking the appeal court to lift the ban, hoping to do some work this year before snow falls.

The controversy has already cost the Mount Graham Observatory the support of its original sponsor, the Smithsonian Astrophysical Observatory, and of every North American university courted as a partner. But Strittmatter thinks the observatory would have faced similar opposition anywhere in the United States. "The irony is that observatory sites are always so benign, almost like wildlife refuges," he says.

Colin Macilwain

\section{Congress directs NASA to plan an asteroid hunt}

Washington. In the aftermath of what some are describing as "comet fever", the US Congress has directed the National Aeronautics and Space Administration (NASA) to develop a plan by next February for a long-term programme to identify comets and asteroids that may pose a threat to Earth.

In an amendment to next year's authorization bill for the space agency, the House of Representatives Science, Space and Technology Committee has instructed it to produce a strategy - including funding requirements up to 2000 - for a programme capable of identifying all objects larger than one kilometre in diameter likely to cross the Earth's orbit within 10 years.

Congress has requested such studies before. Most recently, the Spaceguard Survey, published in 1992, called for a global network of six 2.5-metre telescopes to search the sky for 20 years, at a cost of $\$ 250$ million. But the recommendation was ignored, partly because of its price tag.

Two developments have changed the climate since then. One was last month's impact of Comet Shoemaker-Levy with Jupiter, which brought the reality of cosmic collisions home to the general public. The second has been the willingness of the US Defense Department to share observational facilities that could assist in such a search.

The military already uses a network of upward-looking telescopes called GEODSS (Ground-based Electro-Optical Deep Space Surveillance) to track satellites and debris in Earth orbit. Downward-looking spy satellites have for years been recording meteor flashes in the atmosphere, yielding information on objects that collide with Earth.

Gregory Canavan of the Los Alamos National Laboratory also points out that the military's experience in using instruments equipped with charge-coupled devices for long-term, systematic sky searches could be transferred to an automated asteroid watch

Congress has directed the Department of Defense to work with NASA in developing the search plan, and Pentagon involvement in the search could help ease the funding burden on the space agency. International participation, which Congress has also called for, could bring NASA's costs down even further.

Some have criticized the idea of using nuclear weapons to shoot down or deflect celestial hazards (see Nature 370,$65 ; 1994$ ). But few argue against a programme designed to search for them. Last week, NASA named an eight-member committee to come up with a workable plan. It is headed by Eugene Shoemaker of the Lowell Observatory - co-discoverer of the comet that hit Jupiter last month.

Tony Reichhardt 